\title{
Vargas Vargas, José Ángel (2013) Juan Gabriel, pan y miel. San José, Costa Rica: Litografía e Imprenta LIL. Revisado por M. Ed. Gilberto Chavarría Chavarría ${ }^{1}$
}

\author{
\begin{tabular}{l|l} 
Recibido 31/V/2015 & Aprobado 26/VI/2015
\end{tabular}
}

En la historia de vida de cada uno de nosotros se presentan una serie de acontecimientos que nos permiten formarnos y llegan a constituirse en aspectos medulares para poder entender lo que hoy somos. En este sentido juega un papel fundamental la familia y todas aquellas personas e instituciones que nos rodean. Es el lugar donde crecemos, donde aprendemos a ser, donde formamos nuestra personalidad, así como el principal pilar de nuestro entorno emocional. Los valores como el respeto, la convivencia o la tolerancia se aprenden en ella. La familia además de cubrir las necesidades básicas de alimentación y abrigo, cumple un importante papel en el desarrollo social y emocional de los niños y las niñas en los primeros años de vida.

En este contexto se desarrolla la novela Juan Gabriel, pan y miel, escrita por el Dr. José Ángel Vargas Vargas, un texto que motiva a leerlo desde su sugestiva portada, la cual presenta un título y una ilustración que provoca inferir sus diferentes significados.

El árbol de lunas que ilustra la portada nos invita a explorar el texto con el objetivo de comprender su significación y relacionarla con el título: “Juan Gabriel, pan y miel." Es ahí donde el primer tema nos remonta a la familia y a esos primeros años de vida del personaje principal de la novela, "Juan Gabriel". Primeros años que nos involucra en la historia, porque la similitud en cuanto a los acontecimientos es análoga a la de muchos de nosotros. Esto nos motiva a seguir escudriñando las diferentes aventuras del personaje e ir comprendiendo el porqué del título.

La vida de Juan Gabriel se desarrolla en una familia que recién empieza a formarse y crecer: la de Octavio y Paquita. En ella priman los valores más importantes que puedan tener las personas. El amor, respeto, trabajo, solidaridad, responsabilidad, entre otros, que se visualizan en cada una de las acciones. Así como el árbol de lunas se desarrolla y produce unos frutos fantásticos, también empieza a crecer la familia. En este escenario, poco a poco va creciendo Juan Gabriel y muestra diferentes facetas de la vida que interpelan nuestra realidad. Aparecen las dificultades, pero lo más importante es que con el apoyo de las personas que le rodean, especialmente los padres, éstas se van superando. Es muy destacable la solidaridad de los personajes del pueblo, como doña Alba, doña Anita, la partera, doña Juana, Luco, doña Argelia y doña Lola, entre otras, personas de mucho valor, como también las hay en la actualidad. ¿Quién no recuerda en aquellos tiempos al Dr. Juan Guillermo Ortiz, pionero del Hospital sin Paredes, a Valeriano, al doctor Lobo? Todos ellos muy comprometidos con la labor que realizaban.

\footnotetext{
${ }^{1}$ M. Ed. Gilberto Chavarría Chavarría, profesor de la Universidad de Costa Rica, Sede de Occidente. Correo electrónico gilberto.chavarria@gmail.com.
} 
Es en este sentido que se empieza a esclarecer y comprender el significado que tiene el título de la obra. Porque conforme se avanza en la lectura, se va construyendo un texto paralelo, que podría no coincidir con el del autor. El pan simboliza esas situaciones difíciles con las cuales nos enfrentamos día con día (de salud, económicas, por ejemplo) y la miel, la posibilidad de llegar a tiempos mejores, sinónimo de alegría, salud, bienestar y esperanza.

El libro nos permite rescatar la cultura popular que se reconstruye por medio de la tradición oral y el testimonio. Además de los elementos importantes del patrimonio lingüístico, entre ellos palabras tales como: solar, surco, menesteres, santiguando, amoratado, extenuada, fajazos, cochinada, sancochada.

Por otra parte la novela deja muy "claro" cuál es el papel de la mujer en la época histórica que se narra, la cual por diferentes indicios textuales puede corresponder a la segunda mitad del siglo veinte. La mujer madre, proveedora, figura de autoridad. Muchas de las acciones del protagonista están mediatizadas por el respeto que le tiene a la mamá.

Para el período de la historia en que sucede la trama es notorio el apego de las familias al sentimiento religioso, con el desarrollo de una serie de prácticas como el rezo del rosario, el ir a misa, el rogar a Dios para que todo resulte bien, en fin la vida gira alrededor de una serie de valores espirituales. Además, se muestra un mundo mágico maravilloso cargado de creencias vinculadas con la salud, la fe, la esperanza y el hacer cotidiano de los hombres y las mujeres. Así el dolor humano causado por las enfermedades que hicieron estragos en la Costa Rica de esa época, llevó a las poblaciones a articular la medicina tradicional, los centros hospitalarios y la experiencia especialmente de las madres para evitar la pérdida de un ser querido. La existencia de condiciones insalubres como las aguas cargadas de parásitos, los niños descalzos y que consumían los alimentos sin lavar o en mal estado, hicieron que la mortalidad infantil aumentara.

En fin, el autor, con este texto, que se enmarca en la tradición de la novela picaresca, reconstruye las aventuras e ilusiones del niño protagonista y logra ficcionalizar parte de la sociedad costarricense del siglo pasado, la cual, sin duda nos marcó como personas.

\section{M.Ed. Gilberto Chavarría Chavarría}

Profesor Universidad de Costa Rica 